Lepr Rev (1998) 69, 338-340

\title{
Editorial
}

\section{INTERNATIONAL LEPROSY CONGRESS, BEIJING, 7-12 SEPTEMBER 1998: WORKING TOWARD A WORLD WITHOUT LEPROSY}

The $15^{\text {th }}$ International Congress in Beijing was attended by over 1000 people, 350 of them from the People's Republic of China, where so much progress has been made in recent years towards the aim of basic eradication as described in this journal by Ma Haide and Ye Ganyun in 1982. ${ }^{1}$ International delegates came from virtually all countries where leprosy is still endemic, with an appropriately high representation from India and other parts of South-East Asia, which currently account for over 591,000 of the world total of 828,803 registered cases. $^{2}$

The theme of 'Working Toward a World Without Leprosy' was adopted by the Organizing Committee of the International Leprosy Association at a meeting held 2 years ago and interpreted by the President, Dr Yo Yuasa, as meaning 'a world without leprosyrelated problems, both medical and social, emphasizing the point that it is not the disease per $s e$ but its related problems, mostly social but some medical, which require attention' ${ }^{3}$ The $15^{\text {th }}$ Congress introduced a radically changed format, with emphasis on the need to be forward-looking, action-oriented, integrated and participant-friendly. Pre-Congress workshops were replaced by workshops in the afternoons of the main meeting, and the previous 'state of the art' lectures were replaced by 'Presentation of Current Issues' on the second and fourth days, followed by 'Open Panel Discussion', thus making the morning sessions open to all delegates. Day 5, entitled 'Synthesis', was intended to provide each participant with a broad picture of current and future needs, challenges and possible solutions. One of the main objectives of the Congress and this new, experimental format was to come up with a series of practical recommendations, or even action plans, but to be regarded as 'take-home' lessons rather than official resolutions. In addition, there were, as in previous Congresses, a large number of oral presentations of accepted papers over a 3-day period, together with poster presentations in an exhibition hall, training sessions in the evenings and facilities for nongovernment organizations, drug companies and other agencies to set up posters and distribute information from booths. The Book of Abstracts listed 43 sessions in the Scientific Programme, covering training, epidemiology, control and eradication, psychosocial aspects, clinical aspects, disability control, rehabilitation, surgery, chemotherapy, experimental aspects, immunology, microbiology and pathology. Headings, authors and summaries of an impressive total of 730 abstracts are recorded in alphabetical order according to subject.

Apart from the exhibits put up by individuals each day, several 'permanent' exhibits were 
of outstandingly high quality and importance. One in the main hall of the conference centre was devoted to the story of leprosy control in China, brilliantly researched and illustrated and surely worthy of preservation for archive purposes as a tribute to the almost unbelievable success of control efforts in this vast country in the present century. The same may be said of 'Quest for Dignity. Victory Over Leprosy/Hansen's Disease', a large-scale photographic exhibition on the upper floor of the conference centre, originally shown in the United Nations Building in New York in October-November 1997. It shows, often in stark terms, the conditions in which many patients had to struggle in the second half of the last century, up to fairly recent times, in various parts of the world. A series of more recent photographs shows people affected by leprosy/Hansen's disease who have overcome difficulties and are obviously managing to live in peace and happiness as individual world citizens, some even finding ways to care for those less fortunate than themselves. The pictures of the children, separated from their families and confined to leprosaria in the last century, are unforgettably poignant. An interesting feature of this Congress was the number and range of subsidiary meetings held by various groups and agencies to discuss matters outside the of ficial programme and agenda. One of particular importance was arranged for members of the International Leprosy Association to discuss its future in the light of falling membership figures and the expense of printing and distributing the International Journal of Leprosy. Dr Yo Yuasa was unanimously re-elected as President of the ILA, and in his acceptance speech indicated that he and his Officers would be giving serious attention to this worrying situation in the near future.

With regard to the overall outcome of such a large and expensive event, perhaps the main burden of analysis and summary fell on the shoulders of key speakers in the plenary session, 'Synthesis', on day 5. They addressed 'Disease and Disease Control' (Dr W. C. S. Smith, UK), 'Social Aspects of Rehabilitation' (Dr C. M. Walter, India) and 'Causative Organism and Host Responses' (Dr J. L. Krahenbuhl, USA). Their summaries, while revealing little that was startlingly new, nevertheless focused attention on (1) the highly significant progress which has been made in recent years, much of it due to the implementation of multiple drug therapy, (2) the vital importance of keeping up the pressure with regard to case detection and treatment until the goal of elimination has been achieved, at least at national levels, (3) the need to intensify our efforts with regard to social aspects, rehabilitation, self-care and the acceptance and integration of leprosy patients into all levels of society and (4) the importance of maintaining a research capability in leprosy, to include new molecular and immunological assays to aid diagnosis, improvements in chemotherapy, studies on the pathogenesis of reactions and nerve damage and vaccine research.

Meetings of this kind, bringing together people from so many different parts of the world with interests in almost every conceivable aspect of a complex disease such as leprosy, continue to present a challenge to any reviewer with regard to effectiveness (including costeffectiveness), success or even failure. However, as a gathering of enthusiastic and highly motivated people who would not otherwise have the opportunity to meet, there can surely be little doubt that this Congress, like many before it, was outstandingly successful. At a critical point in the history of this disease, it brought together medical and nonmedical people, learners and experts, field workers and scientists, and gave them the opportunity to find out what more needs to be done to reach the goal of elimination of leprosy as a public health problem as defined by the World Health Organisation, whilst at the same time paying even more attention to the social, psychological and physical needs of those with this disease. 
The first congress was held in Berlin in 1897. Beijing marked the centennial. The next, early in the third millenium, will be in Brazil. Is it even conceivable that it may be the last?

Department of Dermatology

A. Colin McDougall

The Churchill Hospital

Headington

Oxford OX3 $7 \mathrm{LJ}$

United Kingdom

\section{References}

${ }^{1}$ Haide M, Ganyun Y. Leprosy work in China. Lepr Rev, 1982; 53: 81-84.

2 WHO. Action Programme for the Elimination of Leprosy. Status Report 1998. WHO/LEP/98.2. World Health Organisation, Geneva, 1998.

3 Yuasa Y. A reflection on 'Working Toward a World Without Leprosy' (a message from the ILA President). ILA Forum, 1988; 5: 1-4. 